\title{
Language Attitudes and Kiswahili Language Learning in Primary Schools in Kenya
}

\author{
${ }^{1}$ Eric, W. Wamalwa, ${ }^{2}$ Ernest Sangai Mohochi, ${ }^{3}$ Isaac Ipara Odeo, ${ }^{4}$ Frida A. Miruka \\ ${ }^{1,2,3}$ Department of Kiswahili \& Other African Languages, Kibabii University, Kenya \\ ${ }^{4}$ Department of Language and Literature Education, Masinde Muliro University of Science \& Technology, \\ Kenya \\ E-mail of the corresponding author: (ewalela@kibu.ac.ke)
}

\begin{abstract}
Kiswahili and English are two important languages taught and examined at the national level in Kenya's education system. Students' academic performance in the subjects keeps varying in national examinations. Different from English, however, poor performance in Kiswahili is more often associated with negative attitudes. Nevertheless, empirical validations have in most cases, not been established. The present study explores pupils' attitudes toward Kiswahili in the context of second language learning in Siaya County of Kenya. The study is anchored on the assumption that although language attitudes play a big role in second language learning and development, primary school pupils have often been neglected in the investigation of language attitudes despite the fact that Kiswahili language learning and teaching begins at that level. A sample size of 360 class eight pupils randomly picked from 18 primary schools of Siaya County participated in the survey. Data collection was by use of attitude questionnaires and, analysed by mixed method approach. Results showed that primary school pupils had positive attitudes towards Kiswahili. The attitudes were due to the communicative and integrative functions of Kiswahili. Pupils however indicated that English remained instrumental to their academic and future pursuits. Consequently, Kiswahili was not accorded the same weight as English, which in turn influenced negatively Kiswahili language learning. The study calls for creation of awareness about the instrumental value of Kiswahili language to learners. This be done, from the early stages of their academic development. Moreover, it recommends that the culture of using grammatical language by learners be encouraged, as much as it is possible. This will serve to improve their Kiswahili language skills and contribute to good performance.
\end{abstract}

Keywords: Language attitudes, Kiswahili education, integrative/instrumental attitudes, language use patterns

DOI: $10.7176 / \mathrm{JEP} / 11-21-19$

Publication date:July 31 st 2020

\section{Language Attitudes and Second Language Learning}

While the importance of language attitudes for language learning motivation postulated by Gardner and associates was downplayed in the 1990s and, attention shifted to more cognitive and situational factors (Heinzmann, 2013), this trend seems to have been reversed recently as studies have shown that language attitudes influence second language learning (Masgoret and Gardner, 2002; Brown, 2007; Simandan, 2016). The role of language attitudes and motivation in second language learning cannot be over emphasized (Brown, 2007, Ahmed, 2015).

Attitude is defined not as a behaviour, but rather as "preparation for behaviour", a predisposition to respond in a favourable or unfavourable manner to an attitude object, which includes things, places, people, situations or ideas (Oskamp, 1977:8). A considerable number of theories have been developed on the study of language attitudes (see Agheyisi \& Fishman, 1970, pp. 137-149 for a brief review). In the present study, however, we make a theoretical distinction between the behaviourist and mentalist viewpoints. The behaviourist perspective views attitude as a response to a certain situation (Agheyisi \& Fishman, 1970) and considers it a dependent variable that can be statistically determined through observation of behaviour in social situations (Cherciov, 2012). Alternatively, the mentalist perspective views attitudes as a mental and neutral state of disposition (Allport, 1967 cited by Cherciov, 2012), that are not directly observable, but can be inferred from the subject's responses using the right stimuli. A further theoretical distinction between the two theories relates to the unicomponential and multicomponential conception of attitude. To the behaviourists, an attitude has a unicomponential structure, the affective component, while to mentalists, it has three components: the affective, behavioural (conative) and cognitive (Bouzidi, 1986). The affective component refers to emotional reactions while the cognitive to an individual's belief structure and thoughts about an attitude object. The conative component comprehends the tendency to behave in a certain way towards the attitude object (Baker, 1992).

When applied to language studies, language is the attitude object. Therefore, language attitudes are, according to Baker (1992) the feelings people have about their own language or language(s) of others. The notion of attitude in 
language learning rests on a long research tradition, which is matched by an equally broad range of contexts (Bartram, 2010). Different studies have focused on the role of attitudes on first language, second language, foreign language and bi-lingual teaching and learning contexts. The concept is however, usually broadened to cover a variety of specific attitudes, not just attitudes towards certain language varieties. It includes attitudes to language groups, attitudes to certain features of languages, attitudes to language use, attitudes to language variation and attitudes to language learning (Baker, 1992).

Similarly, the effectiveness of second language learning depends on the attitudes of the second language (L2) learners regarding the relevant second language community (Ahmed, 2015). Although these claims are plausible, they do not replicate in all L2 learning contexts. Learning a second language also depends on the importance of the specific language in the context of the learner. Gardner and Lambert (1972) cited in Brown (2007) posit that motivation relates to many types of attitudes. However, in light of their description, the most important tendencies people have towards learning a new language relate to the language community of the language they are learning. This has to do with the attitudes of language learners about the language community of the L2. Positive attitudes will usually provide an incentive to learn a particular language. In addition, negative attitudes about the community provide little or no motivation to learn the language.

Gardner et al (1987) in Masgoret and Gardner (2002) indicate that a student who has integrative attitudes usually has a higher motivation to learn a second language. This stems from the need to integrate with the L2 community. Such a pupil also maintains a positive attitude throughout the language learning process. Conversely, one who has a negative attitude towards language tends to have less motivation in the course of learning a language (Brown, 2000). Moreover, Ahmed (2015) opines that pupils' perceptions of the target culture have an impact on the effectiveness of L2 learning. Gardner (1985) describes this by saying that words, sounds, grammar rules and all that a language teacher tries to teach is more than a linguistic code, they are important ingredients of another culture. As a result, pupils' attitudes of the language community influence the effectiveness of incorporating these aspects of the language.

The importance of attitudes in L2 learning hinges on the argument that if people have positive attitudes toward the language they want to learn, they will have a higher motivation to learn the language. Likewise, if one has a negative attitude, language learning is considered negative. Attitudes are influenced by one's values and belief system, and they contribute to decisions made in all spheres of life (McGroarty, 1996). Consequently, the learning process takes place more easily when the learner has a positive attitude towards language and learning. Moreover, studies show that the effect of attitudes on some aspects related to second language learning are influenced by gender differences, where girls often display more positive attitudes and are more motivated to learn languages than boys (Burstall, 1975; Gagnon, 1974; Gardner and Smythe 1975, cited by Gardner, 1985). Other intervening variables found to influence the formation of attitudes include parental influence, learning and religious institutions, mass media and peer influence Parsons, Adler \& Kaczala, 1982; Saldana, 2013; Vreese \& Moeller, 2013; Philo \& Happer, 2013).

In summary, attitudes play an integral part in L2 learning, growth and development. Although the role of attitudes in L2 learning is immense as has been shown above, only few studies done have focused directly on attitudes towards Kiswahili language. The present study investigates language attitudes and Kiswahili language learning, to explain the evolving learner attitudes and their impact on Kiswahili language learning.

\section{Sociolinguistic Profile of Kenya}

Kenya is a typical multilingual country. However, as Ogechi (2003) notes, it is difficult to state categorically the exact number of languages spoken in Kenya depending on the source one is citing and whether or not one is referring to grammatically stable codes or both grammatically stable and unstable codes. For instance, the Constitution of Kenya Review Commission Report cited by Ogechi (2003) puts the number of languages at 70. Mose (2017) adopts a more general approach, by saying that Kenya has "over 40" indigenous languages besides English and Kiswahili. It is worth noting that Kiswahili is an indigenous language too but it projects a higher status due to its level of development and the functions it performs.

Ethnologue $(2020)^{1}$ lists as 68 , the number of established languages in Kenya. Of these, 67 are living and one is extinct. Moreover, they indicate that of the living languages, 60 are indigenous and seven are non-indigenous, 13 are institutional, meaning the languages have been developed to a point that they are used and sustained by institutions beyond the home and community. Fifteen languages are vigorous, meaning that they are in vigorous

\footnotetext{
${ }^{1} \mathrm{https}: / /$ www.ethnologue.com/country/KE
} 
use among all generations and remain unstandardized. Furthermore, one language is endangered while five are dying.

This variety is a reflection of the country's diverse population that includes most major ethno-racial and linguistic groups found in Africa. Most languages spoken locally belong to two broad language families: Niger-Congo, which is the Bantu branch, and Nilo-Saharan, the Nilotic branch spoken by the country's Bantu and Nilotic populations, respectively ${ }^{2}$. The Cushitic and Arab ethnic minorities speak languages belonging to the separate Afro-asiatic family, with the Hindustani and British residents speaking languages from the Indo-European family.

Kenya's various ethnic groups typically speak their vernacular languages within their own communities. The two official languages, Kiswahili and English are used in varying degrees of fluency for communication with other populations. English is widely spoken in commerce, school and government. Most peri-urban and rural dwellers are less multilingual, with many in rural areas speaking their native languages (Brown, Asher \& Simpson 2006), and Kiswahili, the national language.

\subsection{Kiswahili in Education in Kenya}

Language issues are very central in any educational system. Firstly, language is used as the medium of instruction and secondly, as a subject. Through language, the cultural system of a people is embodied, stored and transmitted to future generations (Batibo, 2005). Functions assigned to a language in education do not only affect the attitudes of members of society to it, but also determine the status accorded to it (Adegbija, 1994). As a result, many language policies arise from the role of language in education. In many African countries, acquisition of education has for a long time been equated to acquisition of knowledge, and fluency in the former colonial masters' languages, which were adopted as media of instruction (henceforth, MOI). As Adegbija (1994) aptly puts it, many Africans believe that colonial masters' languages are superior to their own languages because of their use in matters of science and technology, and current affairs. However, they view indigenous languages as being low in status and deficient in educational discourse. Their use in education is often met with negative attitude and resistance. In this section therefore, the state of Kiswahili in education in Kenya is briefly described in a historical perspective to demonstrate that the attitude problem which affects Kiswahili stems from the past policy statements or pronouncements.

Missionaries introduced formal education in Kenya in the 1840s. At the time, their objective was to use education as channel of spreading the Christian faith. Missionaries, notably John Ludwig Krapf and Johann Rebman's interest in learning and using local languages was high (Mbaabu, 1991). A few years after his arrival, Krapf wrote the first Kiswahili grammar in 1850 (Khalid, 1977). In most of their educational endeavours, Kiswahili was the language of choice. The missionaries established many schools in different parts of the country. Some of these schools like Alliance, Mangu, Maseno and Kamusinga later became centres of excellence in education (Mohochi, 2005), and are still sponsored by the churches that established them.

The arrival of white settlers in 1903 brought about a shift in the earlier policy. A new approach was adopted that segregated Africans and Asians. This new approach was informed by the need expose Africans to only a small level of education that would enable them to participate in the lowest activities in factories and in farming. In 1924, the Phelps-Stocks Commission decried the state of education for Africans and blamed it on lack of consensus on expectations and objectives for education between the missionaries and colonial masters (Gorman, 1974). While missionaries wanted to use Kiswahili, the colonial masters introduced the use of indigenous catchment languages. Soon after the Second World War, the British rulers changed the language in education policy. Although Kiswahili and other African languages had been slated for use in education earlier, emphasis was given to indigenous languages and English (Mazrui \& Mazrui, 1998). The British claimed that Kiswahili was affecting negatively the teaching of English. Seemingly, the colonialists feared the use of Kiswahili, as it was a portentous tool for uniting Africans who had started resisting colonial occupancy and rule. By 1953, it had been decided that English would be the sole language for writing class eight examinations. This decision had a corresponding negative impact on the development of Kiswahili since it was no longer compulsory subject.

After attainment of independence in 1963, several commissions were set up to look into among other issues, language in education. Notable commissions include the Ominde Commission of 1964, Gachathi Commission of 1976 and Mackay Commission of 1981 (Mbaabu, 1996). The Ominde commission recommended the use of English as the MOI over Kiswahili and other local languages. The Gachathi Commission introduced a policy for basic education institutions. This Commission recommended the use of the predominant language spoken in the

2 Ethnologue - Languages of Kenya 
schools' catchment areas as the MOI for the first three years of primary education. Further, it stated that English be introduced as a subject from Primary 1 and, to make it supersede the predominant local language as the MOI in Primary 4. This was only possible in linguistic homogenous areas of the country. In heterogeneous communities however, Kiswahili was to be the MOI for the first three years of primary education. This notwithstanding, in most parts of the country, English was given more emphasis than both vernacular and Kiswahili languages. This policy however faced challenges in its implementation.

Some factors that contributed to lack of full implementation of the policy were the lack of enough trained teachers to handle Kiswahili and vernacular languages. Moreover, it was too costly to develop curriculum materials for all local languages in the country to meet the demand of the time. Kiswahili education continued to suffer from lack of implementation of policy statements until the introduction of the 8-4-4 system of education, which changed the landscape drastically after it was rolled out in 1985 following the recommendations of the Mackay report of 1981. Kiswahili was to be taught as a compulsory subject from primary to secondary schools. Moreover, it was to be examined nationally at both primary and secondary levels. Due to lack of implementation of previous policy statements, many schools in the republic had not given Kiswahili the seriousness it deserved academically, either due to lack of teachers or negative attitudes. The Mackay report changed the landscape nationally as all schools were required to teach the subject effectively (Mbaabu, 1996). Much as now, Kiswahili is taught in all schools in the republic, pupils and students still post poor performance, and many times, negative language attitudes are blamed for it.

It is against this backdrop that this study was done. One of the region that has lagged behind in the development of Kiswahili in Kenya, is Nyanza, which is the research location for this study. The Luo speaking community inhabits Siaya County. To most Kenyan communities, Kiswahili is a second language, save the native Swahili speakers. Luo language is of the Nilotic origin whereas Kiswahili is Bantu. There are past claims that Luos have negative attitudes toward Kiswahili because it is Bantu. Previous studies have shown that residents of Nyanza have negative attitudes to Kiswahili (Mwangi, 1998; Oketch, 2006 in Maloba, 2010 and Owala, 2014). Many of these studies involved students in secondary schools. We note however, that language learning and teaching begins in the earlier stages: pre-primary and primary school stages. Therefore, the formation of language attitudes can occur in primary school. This study is premised on the assumption that learners in primary schools form attitudes towards languages, and that it is important to understand how these attitudes interplay in the language learning. The purpose of this study was to investigate the attitudes of grade eight (class 8) pupils of Siaya County toward Kiswahili language. The research addressed the following questions:

1. What are the language attitudes of class eight pupils toward Kiswahili in the learning context?

2. How do learners' language attitudes affect their Kiswahili language learning?

\subsection{The area of study}

Kenya is sub divided into 47 administrative units called counties. This study was done in Siaya County. Geographically, Siaya County is located in the western region of Kenya. It is 2,530 square kilometres in land size. The county has six sub-counties, namely; Siaya, Bondo, Rarieda, Gem, Ugenya and Ugunja. It borders Busia County to the northwest. To the northeast, it borders Vihiga and Kakamega counties and Kisumu County to the southeast. Linguistically, the native language spoken by residents of Siaya County is Luo. Luo is one of the NiloSaharan languages. Although majority of Siaya county residents are of the Luo community, some counties bordering it have Bantu speaking communities to the northeast and northwest. Some of these Bantu languages spoken are Lunyore, Lusamia, Luwanga, Lunyala and Marachi.

\section{Methodology}

This study adopted a descriptive survey design. The study comprised of 360 pupils, randomly selected from 20 schools of Siaya County. Questionnaires were used to collect data. The questionnaire had two sections. Section 1 solicited biodata. More important information in the section was gender, age, place of birth and residence. Section 2 consisted of the Likert-scale type statements, which elicited pupils' attitudes towards Kiswahili. Twenty statement items were used. Of these, 10 were positive while the other 10 were negative. Five choices i.e. 'Strongly agree', 'Agree', 'Uncertain' 'Disagree', and 'Strongly disagree' were provided for the respondents to pick only one. The positive statements responses were coded as follows: strongly agree (5), agree (4), uncertain (3), disagree (2) strongly disagree (1). The order was reversed for the negative statements. IBM SPSS statistics v23 was adopted for data management and statistical analysis. Also included was a pattern of language use tool, on which were specific domains of language use. The respondents were to show their language preference in each domain by 
selecting the language on the tool. Analysis of data was done by mixed method approach, where both quantitative and qualitative methods were used. Results have been presented in tabular form.

\section{Results and Discussion}

\subsection{Respondents Characteristics}

Of the 360 pupils, $176(49 \%)$ were of the male while 184 pupils, (51\%) were female. In terms of age, $36(10 \%)$ of pupils were 12 years old, 241 pupils (67\%) were between 13 and 14 years old, those between 15 and 16 years were 75 pupils $(21 \%)$ while 7 pupils were above 17 years. This accounted for only $2 \%$. Thus, most participants were, aged between 13 and 14 years. In terms of their place of birth, majority, 55\% were born in upcountry or rural areas, while those born in urban areas accounted for $45 \%$ of the respondents.

\subsection{Pupils' attitudes to Kiswahili}

This study investigated learners' attitude towards Kiswahili language. Table 1 presents the pupils' language attitude index.

Table 1: Pupils' language attitude index

\begin{tabular}{llllllll}
\hline & \multicolumn{7}{l}{ One-Sample T-test } \\
\cline { 2 - 7 } & Mean & Std. Dev. & test value & $\mathrm{t}$ & $\mathrm{df}$ & $\mathrm{p}$-value & Remark \\
\hline $\begin{array}{l}\text { Pupils' } \\
\text { Attitude }\end{array}$ & 4.0388 & 0.44748 & 3.41 & 27.087 & 359 & $0.000<0.05$ & Positive Attitude \\
\hline
\end{tabular}

The overall pupils' attitude mean response of 4.0388 (Std. Dev. $=0.44748)$ was found to be significantly lying in the category of positive attitude [test value $=3.41, t=27.087, d f=359, p$-value $=0.000<0.05]$; this is a clear indication that most of the pupils of primary schools in Siaya County have a positive attitude towards Kiswahili language.

The ANOVA and regression coefficient results show that among all the tested biographical factors: gender, age, residence and place of birth, none of them had a significant effect on the attitude of pupils towards Kiswahili in Siaya County.

Gender had an insignificant influence on the attitude towards Kiswahili in Siaya county as indicated by insignificant model, $\mathrm{F}(1,32)=2.07, \mathrm{P}$-value $=0.160$. It accounted for $1.4 \%$ of the variation in the attitude towards Kiswahili as indicated by $\mathrm{R}^{2}=0.014$. The insignificant unstandardized beta results, $\beta=0.517, t=1.439$, P-value $=0.160$ indicate that the attitude of the male pupils towards teaching Kiswahili in Siaya county is not significantly different from that of female pupils. Past studies on attitudes have indicated that gender influences attitudes (Baker, 1992; Mtawaa, 2017). While examining the impact of gender and parental influence on Saudi students' attitudes towards English, Mtawaa (2017) indicates that although both students and parents have positive attitudes towards English, the means and standard deviations showed that male students had more positive attitudes towards English than their female counterparts did. Many studies have also acknowledged the superiority of female learners attitudes towards foreign language learning when compared to their male counterparts (Henry, 2011; Ryan, 2009). This was however not the case for primary school pupils attitudes towards Kiswahili.

Residence was also found to have an insignificant influence on the attitude towards Kiswahili as indicated by insignificant model, $\mathrm{F}(1,23)=1.52$, P-value $=0.24$. Residence accounted for $10.7 \%$ of the variation in the attitude towards Kiswahili as indicated by $\mathrm{R}^{2}=0.107$. The insignificant unstandardized beta results for "town" ( $\beta=0.854$, $t=1.445$, P-value $=0.162)$ and for "out skirts" $(\beta=-0.04, t=-0.082, \mathrm{P}$-value $=0.935)$ indicates that the attitude of pupils living in "towns" and those living in "out skirts" towards Kiswahili in Siaya county were not significantly different from those of pupils who stay in the rural areas. The assumption here was that pupils in rural areas would tend to have less positive attitudes because rural areas in Siaya are more linguistically homogenous as opposed to urban areas that are somewhat heterogeneous. This result however shows that residence accounted for only $10.7 \%$ difference, which was not significant.

The age of the respondent too was found not to have significant influence on pupils' attitude towards Kiswahili in Siaya county as indicated by insignificant model, $\mathrm{F}(2,31)=1.22$, P-value $=0.309$. It accounted for $5.3 \%$ of the variation in the attitude towards Kiswahili as indicated by $\mathrm{R}^{2}=0.053$. The insignificant unstandardized beta results for "11-12years" ( $\beta=-0.502, t=-1.03$, P-value $=0.311)$ and for " $13-14$ years" $(\beta=-0.596, t=-1.414$, P-value $=0.167$ ) indicates that the attitudes of the pupils in the specified age brackets were not significantly different from those of pupils aged between "15-16 years and "17 years" respectively whose insignificant model was 
$\mathrm{F}(2,251)=721$, P-value $=0.548$. This accounted for $6.9 \%$ of the variation in the attitudes towards Kiswahili as indicated by $\mathrm{R}^{2}=0.069$. This findings show that age difference for pupils in Siaya was not a factor to consider when discussing their language attitudes towards Kiswahili.

Besides identifying the language attitudes held by learners, their language use patterns were studied as a means of validating their attitudes and, as a baseline for predicting future language attitude trends (Nicolle, 2019). The results show that in domains away from school namely, in the market place, church and home, a large percentage of the respondents used Luo language in most of their communication. In church, $41 \%$ used in Luo while Kiswahili was used by $34 \%$, English was the least used language, accounting for only $29 \%$ usage. Likewise, the most widely used language at the market place by pupils was Luo by $56 \%$ of the pupils. It was followed closely by Kiswahili, which was used by $42 \%$ of pupils. English was not widely used, as only $2 \%$ of pupils used it in market place activities.

The language of choice for communication with family members at home was Luo, used by $75 \%$ of pupils. Only $28 \%$ attributed usage to Swahili, while $7 \%$ used English in their communication with family members. The language use patterns however changed and showed a different trend between learners and their friends. Of these, $63 \%$ used Swahili, Luo accounted for 32\% while those who used English were only 5\%. It implies that majority of pupils preferred using Swahili when conversing with friends, although the language spoken was not grammatical. Learners had difficulty speaking fluently. We noted that provided there was communication, learners did not care about levels of grammaticality. The most preferred language for communication between students and their teachers was English. Within this context, English language was used by $70 \%$ of pupils. Only $30 \%$ used Swahili while Luo was not used at all. It is noted that these interactions occurred while at school, which is an official context, and where use of vernacular language is prohibited for pupils from grades four through eighth grade.

The study also sought to determine if the belief among pupils that the language, which they thought, would most benefit them in the future had any influence on their attitude towards Kiswahili. This was important because Kenya being a multilingual community, different languages play different roles. Kiswahili is the only indigenous African language that is taught up to university level besides English. Which is why we wanted to identify what learner think about its instrumental value. The mean response for the two categories of languages thought to be of great importance in future were compared using ANOVA. The null hypothesis was that; $\mathrm{H}_{0}$ : All the means are equal and the alternative hypothesis, $\mathrm{H}_{1}$ : Not all the means are equal. The findings were as shown in table 2 as follows.

Table 2: Influence of the language that would most benefit learner in future on their attitudes towards Kiswahili

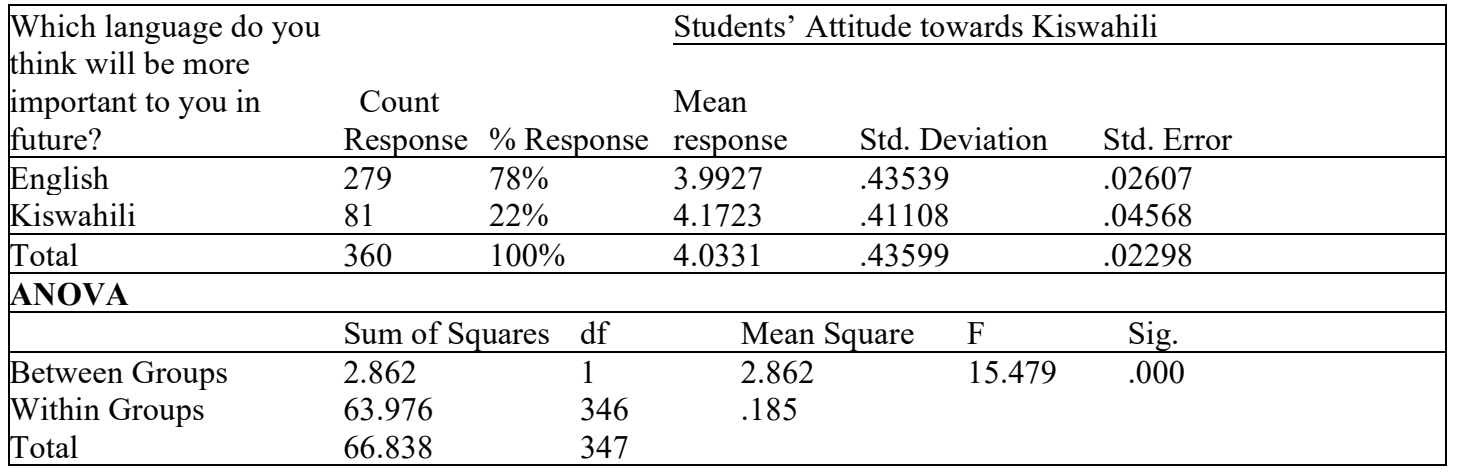

Results in table 2 show that majority of the respondents, $78 \%$ were in favour of English language as the most important language to their future while, $23 \%$ were in favour of Kiswahili. The mean response on the attitude across "English" was 3.9927 (Std. Dev = 0.43539) and for "Kiswahili" was 4.1723 (Std. Dev=0.41108), for which all were categorized as Positive attitude.

The ANOVA results indicate that the mean responses across the two categories as shown in table 2, were all significantly equal $[\mathrm{F}(1,346)=15.479$, p-value $=0.000<0.05]$ therefore accepting the null hypothesis. This indicates that the belief that future importance of a language among pupils had a significant influence on their attitude towards Kiswahili language. Learners who believed that Kiswahili was more important for their future had a significantly higher positive attitude towards Kiswahili [Mean=4.1723, Std. Dev =0.41108] compared to those who believed in English [Mean=3.9927, Std. Dev $=0.43539]$.

The study also assessed teacher influence on learner biasness in terms of study preferences between Kiswahili and English languages among pupils. Results are shown in table 3 below. 
Table 3: Learners language biasness

\begin{tabular}{|lccccc|}
\hline & Language preferred & $\begin{array}{c}\text { Chi-square test for difference in } \\
\text { proportions }\end{array}$ & & & \\
\cline { 2 - 5 } & & English & Kiswahili & $x_{(1)}^{2}$, [p-value] & $\begin{array}{l}\text { Most } \\
\text { significantly } \\
\text { used } \\
\text { language }\end{array}$ \\
\hline $\begin{array}{l}\text { Language emphasized more } \\
\text { teachers while in school }\end{array}$ & by & $82 \%$ & $18 \%$ & $149.511[0.000]$ & English \\
\hline $\begin{array}{l}\text { The language mostly used while in } \\
\text { school }\end{array}$ & $24 \%$ & $76 \%$ & $98.178[0.000]$ & Kiswahili \\
\hline The language you study most & $70 \%$ & $30 \%$ & $55.689[0.000]$ & English \\
\hline
\end{tabular}

The results show that the most significantly emphasized language by teachers in school was English. It was widely recommended by teachers to pupils, to be spoken in school as indicated by $82 \%$ of the respondents, which was significant $\left[x_{(1)}^{2}=149.511, p=0.000<0.05\right]$. Moreover, most pupils attach great importance to it for their future and therefore used most of their time studying it, as indicated by majority of the respondents, $70 \%$ which were significant; $\left[x_{(1)}^{2}=108.90, p=0.000<0.05\right]$ as compared to those who study Kiswahili. It is however interesting to note that much as English was emphasized most by teachers, and although majority of pupils spend most time studying it, Kiswahili was the preferred language for communication, used by $76 \%$ of pupils while in school.

\subsection{Discussion}

Findings of grade eight pupils' attitudes towards Swahili are inconsistent with the findings of recent studies on attitudes to Kiswahili in the wider Nyanza region. For instance, Maloba (2010) and Owala (2014) both concluded that students had negative attitudes towards Kiswahili. Contrary to those previous studies, the current generation has positive attitudes toward Kiswahili. We note that the socio-economic, educational and political dynamics have changed drastically from the time earlier studies were done. The changes have evidently, influenced pupils' attitudes towards Swahili in general. Since the promulgation of the Kenya Constitution 2010, which elevated Kiswahili to the status of official language in Kenya, the populace is seemingly coming to terms with Kiswahili's elevated status and starting to change their previous perceptions. Pupils in primary school are not left behind in this shift.

The patterns of language use have shown that a large number of learners incorporate the use of Kiswahili in their daily communication. Learners showed a lot of use of Swahili in all domains away from school: the market place, church and at home. This is a predictor that there is growing desire for use of Kiswahili beyond the school boundaries in the study area. Moreover, it is an indication of the growing acceptance of the language by local dwellers, which points to changing attitudes towards Kiswahili by the local community at large. There is an increasing realization among respondents about the role of Kiswahili in national development. In the market domain for instance, Kiswahili is increasingly becoming the language of commerce on the local scene. With the advent of county governments in Kenya, many parts of the country continue to experience devolution of government services to the grassroots. These activities are helping to entrench Kiswahili in deep rural areas, as people from diverse ethnic backgrounds get employed in counties, Kiswahili becomes the language of choice in their communicative events.

The findings also show that, much as learners have positive attitudes towards Kiswahili, English is still a challenge to Kiswahili in the academic arena in primary schools. This challenge is occasioned by teacher influence on the pupils. As noted by Schulz (2001) and Xu (2012), teacher perceptions highly influence learners' language attitudes. Most teachers insist that Kiswahili, being an African language is not as important as English. This assertion influences learners' decisions in terms of the language they put more effort in during their personal study times. This has a negative impact on the development of Kiswahili. Thomas \& Roberts (2011) report a similar tendency where learners had positive attitudes to English and Welsh, but preferred English more due to its instrumental value than Welsh. There is a positive aspect of this relationship however, with regard to Kiswahili that, although most learners perceive English to have greater instrumental value, they mostly use Kiswahili for integrative functions. Pupils' positive attitudes to Kiswahili hinge on their knowledge that Kiswahili is not only a national language, but is a language of wider communication across different cultures. Edwards (2009) and Baker (1992) aptly describe this when they posit that besides being directly related to learners' motivation, the perception of the importance of a language is assumed to be related to their attitudes. 
Finally, findings show that the perceptions of learners towards an African language in a multilingual setting are progressively changing. There are other multilingual communities in Kenya, which face similar challenges to one highlighted in this study. The prevalence of positive attitudes is proof that Kiswahili language should not just be learned academically and professionally, it should be strategically supported and empowered in other multilingual communities.

\section{Conclusion and recommendations}

The study has shown that primary school pupils in Siaya have positive attitudes towards Kiswahili; contrary to general opinions previously held. The study has revealed that although learners have positive attitudes, Kiswahili language learning still faces challenges. The language is used for general communication and integrative functions but is not accorded seriousness given to English in language learning. In so much as the language has shown signs of acceptability, as widely used in various social domains, the spoken Kiswahili used is not grammatical, an indication that little is being done in the school setup to inculcate proper language use norms among the users by instilling models of grammatical use of language.

From the aforementioned realities, we recommend the following: Firstly, there is need to create awareness about the instrumental value of Kiswahili language to learners from the early stages of their academic development. All should view Kiswahili, not as a language for communication and social integration only, but as a legitimate career progression path. Career teachers and masters need to create awareness about careers and job opportunities that Kiswahili studies offer. This will inculcate seriousness in Kiswahili language learning both, on the part of the teacher and the learner, and improve instrumental attitudes towards Kiswahili.

Secondly, grammatical use of language is an essential element in language learning. Moreover, it plays a role in fostering positive attitudes, as evidenced in studies that have employed matched guise techniques (Baker, 1992). Besides, correct use language is important for good academic performance. We recommend therefore, that learners be encouraged to speak grammatical language as much as it is possible. This can be achieved by establishing a reward system, where learners who show daily, weekly or termly progress are identified and rewarded.

\section{References}

Adegbija, E. (1994). Language Attitudes in Sub-Saharan Africa: A Sociolinguistic Overview. Clevedon: Multilingual Matters Ltd.

Agheyisi, R. \& Fishman, M. (1970). Language Attitude Studies: A Brief Survey of Methodological Approaches. Anthropological Linguistics, Vol. 12, No. 5 pp 137-157.

Ahmed, S. (2015). Attitudes towards English Language Learning among EFL learners at UMSKAL. Journal of Education and Practice, 6-16.

Aziakpono, P. (2007). The Attitudes of Isixhosa speaking Students Towards various Languages of Learning and Teaching at Rhodes University. Rhodes University: Masters Thesis.

Baker, C. (1992). Attitudes and Language . Clevdon, UK: Multilingual Matters.

Bartram, B. (2010). Attitudes to Modern Foreign Language Learning. London \& New York: Continum International Publishing Group.

Batibo, H. (2005). Language Decline and Language Death in Africa: Causes, Consequences and Challenges. New York: Multilingual Matters Ltd.

Bouzidi, H. (1989). Language Attitudes and Their Implications fot Education: Morocco as aCase Study. University of Glasgow: PhD Thesis.

Brown, D. (2000). Principles of Language Learning and Teaching, 4th Edition. New York: Longman.

Brown, E. K., Asher, R.E \& Simpson, J. M. Y. (2006). Encyclopedia of Language \& Linguistics, Volume 1, Edition 2. Elsevier.

Brown, L. V. (2007). Psychology of Motivation. New York: Nova Publishers.

Cherciov, M. (2012). Investigating the Impact of attitude on first Language Attrition and Second Language Acquisition from a Dynamic Systems Perpective. International Journal of Bilingualism.

Crystal, D. (2000). Language Death. Cambridge: Cambridge University Press. 
Edwards, J. (2009). Language and Identity: An Introduction. New York: Cambridge University Press.

Gardner, R. C \& Lambert, W. E. (1972). Attitudes and Motivation in Second Language Learning. Rowley, Massachusetts: Newsbury House Publishers.

Gardner, R. C. \& MacIntyre, P. D. (1993a). A Student's Contribution to Second Language Learning. Part II: Affective Variables. Language Learning, 26(1), 1-11.

Gardner, R. C. (1985). Social Psychology and Second Lnguage Learning: The Role of Attitudes and Motivation. London, UK: Edward Arnold.

Gorman, T. (1974). The Teaching of Language at Secondary Level . In Whiteley, Language in Kenya. Nairobi: Oxford University Press.

Heinzmann, S. (2013). Young Language Learners' Motivation and Attitudes. Lucerne: Bloomsburry Academic.

Henry, A. (2011). Gender Differences in Second Language Motivation: A Reassessment. In S. Davis, Gender Gap: Causes, Experiences and Effects (pp. 81-102). New York: Nova Science.

Kevogo, A.U., Kitonga, N. N. \& Adika, S. K. (2015). Multilingualism and Language Use Patterns: Students Attitudes Towards Kiswahili in Garisa Town, Kenya. Research on Humanities and Social Sciences, 185-193.

Khalid, A. (1977). The Liberation of Swahili from European Appropriation. Nairobi: East African Literature Bureau.

Maloba, M. (2010). The Influence of Students Attitudes Towards Learning Kiswahili on their Performance in Rachuonyo District: Strategies, Programmes and Clubs for Attitude Change. International Conference on Bilingualism and Teaching. Kenyatta University.

Masgoret, A. M., \& Gardner, R.C. (2003). Attitudes, Motivation and Second Language Learning: A Metaanalysis of Studies Conducted by Gardner and Associates. Language Learning, 53(1), 167-210. doi:10.1111/1467-9922.00227.

Mazrui, A. A \& Mazrui, A. M. (1998). The Power of Babel: Language and Governance in the African Experience. Kampala: Fountain Publishers.

Mbaabu, I. (1991). Historia ya Usanifishaji wa Kiswahili. Nairobi: Longman Kenya.

Mbaabu, I. (1996). Language Policy in East Africa. Nairobi: Education Research and Publication.

McGroarty, M. (1996). Language attitudes, motivation and standards. . In S. \&. In McKay, Sociolinguistics and language teaching. Cambridge: Cambridge University Press.

McGroarty, M. (1996). Language attitudes, motivation, and standards. In H. \&. McKay, In Sociolinguistics and Language Teaching. Cambridge: CUP.

Moeller, J. \& Vreese Claes de. (2013). The Differential Role of the Media as an Agent of Political Socialization in Europe. European Journal of Communication, 28(3), 309-325.

Mohochi, E. S. (2005). Mielekeo ya Wanafunzi Kuhusu Lugha ya Kiswahili na Athari zake katika Matokeo ya Mtihani wa Kiswahili wa Kidato cha Nne Katika Mikoa ya Pwani na Nyanza. Chuo Kikuu cha Egerton: Tasnifu ya Uzamifu.

Mose, P. N. (2017). Language-in-Education Policy in Kenya: Intention, Interpretation, Implementation. Nordic Journal of African Studies, 26(3): 215-230.

Mtawaa, J. B. (2017). Examining the Impact of Gender and Students' Parents on Attitudes towards English: The Case of Saudi Arab Students and Their Parents in Al-Kamel College of Science and Arts. International Journal of Social Science and Humanity, Vol. 7, No. 4.

Muthwii, M. (2002). Language Policy and Practices in Education in Kenya and Uganda. Nairobi: Phoenix Publishers. 
Mwangi, P. (1998). Uhusiano Uliopo kati ya Mitazamo ya Lugha ya Wanafunzi wa Kidato cha Nne na Utendaji wao: Hali ya Kiswahili katika Tarafa ya Maseno. Chuo Kikuu cha Moi: Tasnifu ya Uzamili.

Nicolle, S. (2019). Sociolinguistics: Multilingualism and Diglossia. Retrieved from Academia.edu: http:/www.academia.edu

Ogechi, N. (2003). On Language Rights in Kenya. Nordic Jourrnal of African Studies, 23: 277-295.

Oskamp, S. (1977). Attitudes and Opinions. Englewood Cliffs, NJ: Prentice-Hall.

Owala, J. A. (2014). Mitazamo Kuhusu Kiswahili Miongoni mwa Wazungumzaji wa Kijaluo: Kifani cha Shule za Msingi Katika Kaunti ya Migori. Chuo Kikuu cha Nairobi: Tasnifu ya Uzamili.

Philo, G. \& Happer, C. (2013). The Role of Media in the Construction of Public Belief and Social Change. Journal of Social and Political Psychology, Vol. 1 (1), 321-336.

Ryan, S. (2009). Ambivalence and Commitment, Liberation and Challenge: Investigating the Attitudes of young Japanese people towards Learning of English. Journal of Multilingual and Multicultural Development 30(5), 405-420. doi: 10.1080/0143463092928447.

Saldana, J. (2013). Power and Conformity in Today's Schools . International Journal of Humanities and Social Sciences, Vol. 3(1), 228-232.

Schulz, R. (2001). Cultural Differences in Student and Teacher Perptions Concerning the Role of Grammar Instruction and Corrective Feedback. The Modern Language Journal, 85, 2, 244-258.

Simandan, R. (2016). Determinig the Influence of Attitude Toward Teacher's Accents on Language Learning. Journal Plus Education, 111-140.

Thomas, E. M., \& Roberts, D. B. (2011). Exploring Bilinguals' social use of Language inside and out of the Minority Language Classroom. Language and Education, 25(2), 89-108 doi:10.1080/09500782.2010.544743.

Xu, L. (2012). The Role of Teachers' Beliefs in the Language Teaching-Learning Process. Theory and Practice in Language Studies, Vol. 2 no. 7. 